\title{
US Army Medical Research and Material
} Command

National Cancer Institute

\section{Source}

National Cancer Institute. US Army Medical Research and Material Command. NCI

Thesaurus. Code C39560.

The US Army Medical Research and Materiel Command (USAMRMC) is a component of Department of Defense (DOD) managing biomedical research programs that are part of the DOD and Army budget submission. As directed by Congress, the USAMRMC manages congressionally targeted biomedical research programs. 